\section{Fossil Cryptogams*}

I DO not propose at present to controvert in detail all the positions taken up by my friend Prof. $\mathrm{McNab}$ in his brief communication to your pages on "Fossil Cryptogams" (vol. vii. p. 267), because the time has not yet arrived for doing so. Much more detailed information respecting the subject which yet awaits publication must be had before it can be discussed in a satisfactory manner. I merely wish to avoid leaving the impression, by my silence, that I either admit his supposed facts or accept his inferences. When his paper, to which he refers, was read in Edinburgh, specimens of sections of Calamites of various ages were sent down by me for the purpose of being exhibited to the Botanical Society. This was done by Prof. Dickson, who at the same time expressed his preference for my views over those of $\mathrm{Dr}$. McNab, as is stated in the officially published notice of the meeting in question. Since then I have received a kind letter from Dr. Balfour, who has carefully examined the specimens referred to, and who also expresses a similar conviction. I think that $\mathrm{I}$ have unmistakeable proof of the circumferential growth of Calamites, which Dr. Macnab denies, in specimens of large size, and in which the exogenous zone is of great thickness.

Prof. McNab speaks of "the moist nature of the soil in which the Calamites must have grown," as probably causing a different mode of growth in them, to that "circumferential" one which he admits has probably taken place in Lepidodendra, Sigillariæ, and Dictyoxylons; but I beg to suggest that we have no reasons for thinking otherwise than that these plants grew side by side, and under precisely the same physical conditions, hence the "moist soil" of my friend is an assumption. This close association of Calamites with Sigillariæ was demonstrated and commented upon by Mr. Binney many years ago. Dr. McNab further separates Lepidodendron from Sigillaria and Stigmaria, placing them in different groups. When he receives my third memoir in the Philosophical Transactions (which is printed but not yet circulated), he will see how utterly this plan of procedure is opposed to the facts. I contend that Sigillariæ are virtually Lepidodendra, and that Stigmaria is equally the root of both. As to the location of my old, but now abandoned genus, Dictyoxylon, the more I study it the less I feel competent to fix its true place amongst the Cryptogams. But notwithstanding Dr. McNab's idea as to its coniferous affinities, I venture to affirm, from a prolonged study of a cabinet full of specimens, that its woody axis is not one bit more exogenous than those of Calamites and of matured Lepidodendra. The fact is that whatever the vessels of these various exogenous woody zones signify, they must stand or fall together. They are either all ligneous or they are all cortical. I think that my forthcoming illustrations of the bark-structures amongst the Burntisland Lepidodendra, as well as of our Lancashire specimens, will show that all the elements which Dr. McNab finds in Lycopodium Chamæcyparissus are present, in their proper places, the schlerenchyma of the hypoderm being especially well represented, yet it is precisely this hypoderm with which Dr. $\mathrm{McNab}$ believes my exogenous layer to correspond. There is one if not two distinct layers of cortical parenchyma between this schlerenchymatous layer and my ligneous zone, which latter is so magnificently represented in these plants.

The intimate structure of these latter layers, whether we regard the forms and arrangements of the entire woody wedges or that of their component tissues, is so identical in the two cases of Calamites and Lepidodendra, that an active imagination alone cane other cortical. Dr. $\mathrm{McNab}$ draws a distinction between vessels representing ("feebly") the fibro-vascular bundles of the living Equisetums, in the Calamites, and the more external portions of each woody wedge, which he regards as representing the hypoderinal schlerenchyma of Mettenius. I unhesitatingly avow that there is no ground-whatever for this arbitrary separation. He is putting asunder things which have been joined together from the beginning of time. The tissues in question are as identical in their structure as they are uninterruptedly continuous in their arrangement.

Whilst I am thus opposed to Dr. McNab both on questions of fact and of inference, I feel obliged to him for calling my attention to this possible explanation of the facts, even though after a careful study of his view's I feel constrained to reject them so far as the interpretation of Calamites are concerned. On the questions relating to Meristem growths, we are much

* We regret that the insertion of this letter has been so long delayed in consequence of the great pressure upon our space. nearer to mutual agreement, and I accept thankfully his admiss on of the coniferous affinities of Dictyoxylon, not because I am prepared to recognise any specially close coniferous relationships, but because Dr. McNab's idea necessarily involves an admission of the existence of exogenous features in these plants ; yet I contend that the Dictyoxylons are neitber more coniferous nor more exogenous than most of the other Cryptogamic carboniferous stems which exhibit equally strong proofs of a similar exogenous growth. But I again repeat that we shall not be in a position to grapple philosophically with these problems until all the results of my prolonged researches are published. This is being accomplished as rapidly as my limited leisure admits of. When completed, I shall be quite prepared to enter, if necessary, and in a friendly spirit, upon the entire controversy.

Owens College

\section{Leaf Arrangement}

AfTER reading Dr. Airy's paper on Phyllotaxis (NATURE, vol. vii. p. 343), I cannot see that we are at all nearer than before, any satisfactory explanation as to the inherent cause of it. Let the question be put thus :-If we can conceive, as all will admit, the possibility of leaves being scattered anyhow along a branch, why are they not so, but in some strictly mathematical order? Any disturbance in that order is usually so slight and trivial (due apparently in part to the conical nature of the axis, and unequal growth or slight twists; and which thereby cause certain leaves to assume slightly wrong positions), that it does not destroy the fact that they absolutely are arranged, and can be represented, mathematically.

In my paper on the angular divergences of the Jerusalem artichoke (Linnean Trans. vol. xxvi. p. 647), $Y$ pointed out that two questions might represent all that is required to be solved. (I) That if a leaf be selected as No. I, then No. 2 lies within a certain arc, viz. :- $120^{\circ}-180^{\circ}$ from $N o$. $\mathbf{I}$, for the ordinary series of fractions, and which it does not transgress-why is this? (2) If we allow that arc-why does the second leaf not assume any spot, but is rigidly confinea to a certain angular distance from the first?

I cannot think with Dr. Airy that " the way in which all the spiral orders may have been derived from one original order [was] by means of different degrees of twist in the axis." For if we take a piece of round elastic as he describes, with balls fixed according to some spiral arrangement-say $\frac{2}{5}$-then the successive balls will lie at an angular distance of $144^{\circ}$; and if No. $r$ be fixed and we twist the indiarubber at No. 2, we may cause it to make a complet rotation if we choose.

If, now, his idea of "twist" be admitted as a vera causa of phyllotaxis, we may ask, what causes the twist to be just so much and no more as to make No. 2 pass through $9^{\circ}$ (the angular divergence of $\frac{3}{8}$ being 135 ), so as to pass into the next $\frac{3}{8}$ arrangement? To say that som $*$ such point is a "position of maximum stability" seems to me to give a fictitious importance to the idea of twist, for the expression conveys no really explanatory meaning at all.

Again, to admit that it does not accurately hit the right place, and is in consequence more like Nature, is equally delusive, for Nature is quite accurate enough to be represented mathematically, whereas the positions taken up by the balls must be arbitrary, or at least in proportion to the twist given by the hand-a perfectly arbitrary force? Moreover he appears to overlook the fact that if an axis becomes twisted the fibres will be twisted also, but they are not so; the elastic band he adopts would, if it were a pliant shoot, contort the vessels and wood fibres, a condition not obtaining in nature.

Nor can I agree with him in deducing all the members of the series from $\frac{1}{2}$. My experience leads me to infer they are derived from opposite leaves, such as one finds in the cotyledons. In the Jerusalem artichoke opposite leaves are frequently succeeded by $\frac{2}{5}$; and this is obtained by the pair of leaves, next above the strictly opposite pair, converging to one side, the next pair do so still more, when it will be found that the $\frac{2}{5}$ arrangement will be henceforth established; the internodes having become more and more developed at the same time.

I strongly suspect the original arrangement to have been whorled and quincuncial. This is at least very abundant, if not universal, in coal plants. The whorls may have subsequently become reduced to fours, threes, and twos or decussate. We see this tendency to symmetrical reduction in many existing plants, e.g. stamens and carpels of Cruciferce: Circae as com- 